\title{
THE GLOBAL SEA LEVEL OBSERVING SYSTEM (GLOSS)
}

Merrifield, M. ${ }^{(1)}$, Aarup, T. ${ }^{(2)}$, Allen, A. ${ }^{(3)}$, Aman, A. ${ }^{(4)}$, Caldwell, P. $^{(1)}$, Bradshaw, E. ${ }^{(5)}$, Fernandes, RMS. ${ }^{(6)}$, Hayashibara, H. ${ }^{(7)}$, Hernandez, F. ${ }^{(8)}$, Kilonsky, B. ${ }^{(1)}$, Martin Miguez, B. ${ }^{(2)}$, Mitchum, G. ${ }^{(9)}$, Pérez Gómez, B. ${ }^{(10)}$, Rickards, L. ${ }^{(5)}$, Rosen, D. ${ }^{(11)}$, Schöne, T. ${ }^{(12)}$, Szabados, M. ${ }^{(3)}$, Testut, L. ${ }^{(13)}$, Woodworth, P. ${ }^{(5)}$, Wöppelmann, G. ${ }^{(14)}$, Zavala, J. ${ }^{(15)}$

(1) University of Hawaii, Department of Oceanography, 1000 Pope Road, Honolulu, Hawaii 96822, USA Email: markm@soest.hawaii.edu; caldwell@hawaii.edu; kilonsky@hawaii.edu

(2) UNESCO IOC (United Nations Educational, Scientific and Cultural Organization/Intergovernmental Oceanographic Commission), 1 rue Miollis, F-75732 Paris Cedex 15, France, Email: t.aarup@unesco.org,

b.martin-miguez@unesco.org

(3) NOAA (National Oceanic and Atmospheric Administration), Center for Operational Oceanographic Products and Services (CO-OPS) 1305 East-West Highway, Silver Spring, MD 20910-3281 USA, Email: Allison.Allen@noaa.gov, Mike.Szabados@noaa.gov

(4) Cocody University, UFR SSMT - LAPA MF (Sciences des Structures de la Matière et Technologie - Laboratory of Atmospheric Physics Fluid Mechanics), 22 BP 582 Abidjan 22 Côte D'Ivoire, Email: aman_angora@hotmail.com

${ }^{(5)}$ British Oceanographic Data Centre/Proudman Oceanographic Laboratory, Joseph Proudman Building, 6 Brownlow Street, LiverpoolL3 5DA United Kingdom,Email:elizb@bodc.ac.uk, ljr@bodc.ac.uk, plw@pol.ac.uk

${ }^{(6)}$ UBI (University Beira Interior), CGUL (Centro de Geofisica da Universidade de Lisboa), IDL (Instituto Dom Luís), Rua Marquês d'Ávila e Bolama, 6201-001Covilhã Portugal, Email: rmanuel@di.ubi.pt

(7) Japan Meteorological Agency, 1-3-4 Otemachi, Chiyoda-ku, Tokyo 100-8122 Japan, Email: tide@climar.kishou.go.jp

${ }^{(8)}$ Flanders Marine Institute, Wandelaarkaai 7, B-8400 Oostende Belgium,Email: tjess@vliz.be

${ }^{(9)}$ University of South Florida, 140 7th Avenue South, St. Petersburg, FL 33701 USA, Email: mitchum@marine.usf.edu

${ }^{(10)}$ Organismo Público Puertos del Estado, Avda. del Partenón 10 - 28042 Madrid Spain, Email: bego@puertos.es

${ }^{(11)}$ Israel Oceanographic and Limnological Research, Tel Shikmona, POB 8030, Haifa 31080 Israel, Email: rosen@ocean.org.il

${ }^{(12)}$ Helmholtz-Zentrum Potsdam Deutsches GeoForschungsZentrum GFZ, Potsdam, Telegrafenberg, 14473 Potsdam Germany, Email: tschoene@gfz-potsdam.de

${ }^{(13)}$ Laboratoire d'Océanographie et de Géophysique Spatiale, 14 Ave. Edouard Belin, 31400 Toulouse France, Email: laurent.testut@legos.obs-mip.fr

${ }^{(14)}$ LIENSs (Littoral Environnement et Sociétés), CNRS - Université de La Rochelle, 2 rue Olympe de Gouges, 17000 La Rochelle France, Email: gwoppelm@univ-lr.fr

${ }^{(15)}$ Universidad Nacional Autonoma de Mexico Centro de Ciencias de la Atmósfera, Circuito Exterior s/n, Ciudad Universitaria, Coyoacán, 04510 México D.F Mexico, Email: jzavala@atmosfera.unam.mx

\section{OVERVIEW}

Sea level is one of the most useful oceanographic parameters. Sea level data are vital to scientists for studies of fluctuations in major ocean currents and global climate change, to engineers for the design of coastal installations, to a large community engaged in what is now called 'operational oceanography' (e.g. the provision of flood warnings from storm surges and tsunamis), and in local applications such as provision of tide tables and real-time data for port operations. For nearly 25 years, the Global Sea Level Observing System (GLOSS) has provided oversight for the operation of tide gauge networks and has ensured that requirements for accuracy, frequency and latency of sea level data are met for a broad base of users. After a brief background of the program, we present a status report of GLOSS in 2009, and provide community recommendations for the future role of GLOSS in the coming decade.

\section{BACKGROUND}

GLOSS http://www.gloss-sealevel.org/) was established in 1985 by the Intergovernmental Oceanographic Commission (IOC) of the United Nations Educations, Scientific and Cultural Organization (UNESCO) to provide oversight and coordination for global and regional sea level networks in support of oceanographic and climate research. GLOSS remains under the auspices of the IOC and is one of the observing components under the World Meteorological Organization (WMO)-IOC Joint Technical Commission on Oceanography and Marine Meteorology (JCOMM). GLOSS is an example of a global coastal observing network and among existing observing elements in GOOS (Global Ocean Observing System) it has the largest participation of member states $(\sim 70)$. 
Various networks of tide gauges contribute to GLOSS, each with a different focus. The main component is the GLOSS Core Network (GCN), an evenly distributed set of $\sim 300$ coastal and island tide gauge stations that serve as the backbone of the global network (see http://www.glosssealevel.org/station_handbook/index.html for information on the GCN). Research quality datasets from the $\mathrm{GCN}$ have been used in a number of oceanographic and climate studies [4]. Other GLOSS designated networks have focused on Long Term Trends (LTT) and the stability of satellite altimetry data (ALT) [3], as well as various aspects of ocean circulation (OC) [7]. In support of the World Climate Research Programme (WCRP), GLOSS designated 170 stations to serve as the sea level network for the Global Climate Observing System (GCOS). Data from the GCOS and similar networks have been used for global sea level rise estimates, which compare well with rates from satellite altimetry [2].

Tide gauge data from the GLOSS networks are assembled and archived at two data centers. The British Oceanographic Data Center (BODC, http://www.bodc.ac.uk/) is responsible for delayed mode datasets and for ensuring that GLOSS station data are transferred to the Permanent Service for Mean Sea Level (PSMSL, http://www.pol.ac.uk/psmsl/), the main archive for historic, monthly-averaged and sea level records from tide gauges from around the world [8]. The University of Hawaii Sea Level Center (UHSLC, http://uhslc.soest.hawaii.edu/) collects, assesses, and distributes fast delivery and near real-time datasets obtained via the Global Telecommunications Service (GTS) and other means. The UHSLC also collaborates with the National Oceanic and Atmospheric Administration (NOAA) National Oceanographic Data Center (NODC) to maintain the Joint Archive for Sea Level (JASL). The database consists of research quality hourly and daily values for GLOSS and non-GLOSS stations. The data are annually submitted to the PSMSL, BODC, and the World Data Center system via NODC. The GLOSS data centers have contributed data assembly and quality assessment support for international scientific programs such as TOGA (Tropical Ocean Global Atmospheres), WOCE (World Ocean Circulation Experiment), CLIVAR (Climate Variability and Predictability), and GODAE (Global Ocean Data Assimilation Experiment).

GLOSS has sought to define land motion at tide gauges through collaboration with the International GPS (Global Positioning System) Service for Geodynamics (IGS, today International GNSS Service) in its GPS Tide Gauge Benchmark Monitoring Project (TIGA) [5]. Geocentric coordinates of the tide gauge benchmarks (TGBMs) are required if the tide gauge measurements are to be located within the same global geodetic reference frame as e.g., altimeter data or to establish a global vertical reference frame. Fixing the TGBM to a longterm stable geocentric reference frame like the International Terrestrial Reference Frame (ITRF) allows a multitude of new applications for tide gauge data. The main advantage is to convert the relative sea level readings to fixed referenced time series. This allows for altimeter calibration, the establishment of a consistent World height datum, the estimation of absolute ocean currents between different tide gauge locations, or climate related studies of sea level change. The combination of the vertical uplift and sea level time series also supports studies of global isostatic adjustment (GIA) and tectonics. Geodetic technologies, especially GPS in continuous mode, have improved the accuracy of vertical land motion measurements at tide gauges, whether due to GIA or to other regional or local land motion processes. Reference [10] showed that using a global-scale, fully consistent processing strategy throughout the entire GPS data span considerably reduced technique errors and analysis artefacts, providing useful vertical velocities to account for land motions in tide gauge records.

In appreciation of the multiple uses of tide gauges, GLOSS has also sought to provide water level data that meets the standards and requirements for tsunami warning and storm surge monitoring. Numerous GCN stations have for many years contributed to the Pacific Tsunami Warning System (PTWS) and, following the 2004 Sumatra Earthquake, the IOC and GLOSS have taken an active role in coordinating and implementing the water level network for the Indian Ocean Tsunami Warning System (IOTWS) and the Caribbean Early Warning System (CARIBE EWS).

\section{GLOSS IN 2009}

The status of the GCN has improved substantially in the last decade, primarily in terms of the increase in near real-time stations (166 compared to 72, Fig. 1).

Of the 290 stations in the GCN, 220 (76\%) have provided data recently to one of the GLOSS Data Centers.

Approximately $57 \%$ of the GCN stations are providing data in near real-time via the Global Telecommunication System (GTS) or the Internet. Data are received in "Fast Delivery" mode (within $\sim 1$ month) from 193 stations (67\%). 131 stations have continuous GPS or Doppler Orbitography Integrated by Satellite (DORIS) equipment at or near the tide gauge (see http://www.sonel.org/-CGPS-TG-Survey.html for a full list of GPS and DORIS stations at tide 
gauges).

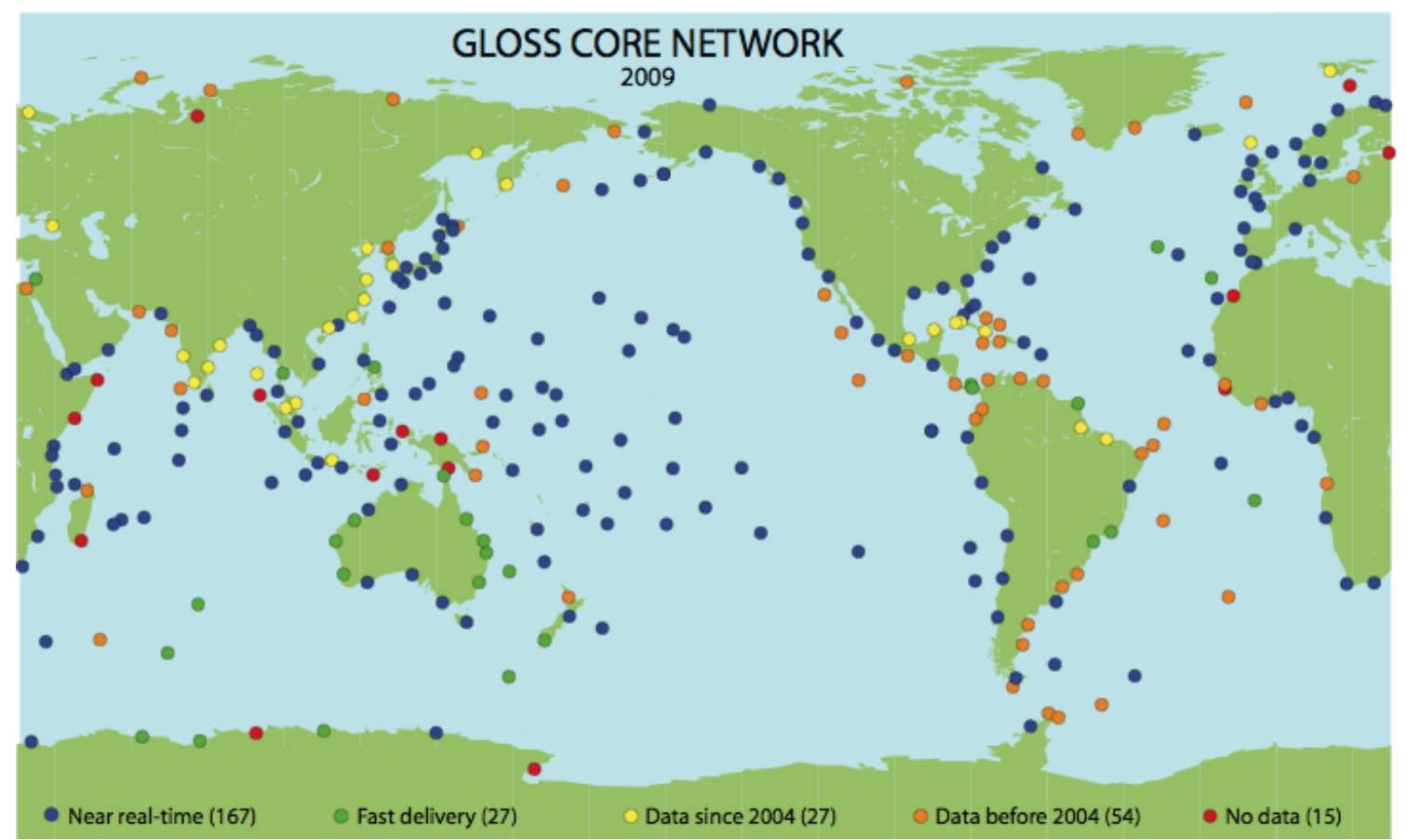

Figure 1. Status of reporting of the sea level gauges in the GLOSS Core Network in 2009 (top) and 1999 (bottom). "Near real-time" and "Fast Delivery" stations provide high frequency sea level (hourly or better reports) which are necessary for understanding of sea level variability in addition to mean sea level rise. Near real-time stations (blue) provide data typically within 1 hour of collection; Fast delivery (green) within one month. Delayed mode low frequency data within 5 years (yellow) or greater (orange) include monthly averages provided to the Permanent Service for Mean Sea Level (PSMSL).

GLOSS relies on the voluntary participation of national agencies to operate and maintain tide gauges to GLOSS standards, and to ensure the quality of the fast delivery and delayed mode datasets. At present nearly 70 nations contribute data to the GLOSS program, with substantial contributions from NOAA, the National Tidal Centre (NTC) Australia, the Japan Meteorological Agency (JMA), the Proudman Oceanographic Laboratory (POL) U.K., and the Service Hydrographique et Océanographique de la Marine (SHOM) (see http://www.vliz.be/gauges/ for a list of real time data providers).

Important contributions to GLOSS in the last decade have come from the development of regional densified sub-systems, such as the MedGLOSS sea level network in the Mediterranean and Black Seas (http://medgloss.ocean.org.il/, developed jointly by the IOC/UNESCO and the Science Commission for the Mediterranean) and the European Sea Level Service (ESEAS). Both bodies cooperate with and contribute to the Tsunami Early Warning and Mitigation System in the North-East Atlantic, the Mediterranean and connecting seas (NEAMTWS) developed by IOC/UNESCO, via equipment upgrades for real time data provision.
Two regional components of the GCN that have undergone considerable improvement in recent years are the Indian Ocean/Southeast Asia region, and greater Africa. Tide gauge upgrades and new installations in the Indian Ocean have been carried out under the auspices of the IOTWS, with ongoing technical support and network coordination provided by GLOSS. More than 50 tide gauge stations are now reporting sea level data in real time (Fig. 2). Several countries have plans for further expansion of their national networks.

Since 2003 through the combined efforts of the Ocean Data and Information Network (ODINAFRICA), the Government of Flanders (Belgium), the IOC, GLOSS, and national and international partners, significant progress has been made in improving the tide gauge network along the African continent and on nearby islands. Nine new stations have been constructed with three more planned by the end of 2009 , and nearly 20 existing stations have undergone substantial upgrades to full operational status. Information on the network (equipment types and location, reports, trainings etc) is available on the African Sea Level Network website (http://www.iode.org/glossafrica). 


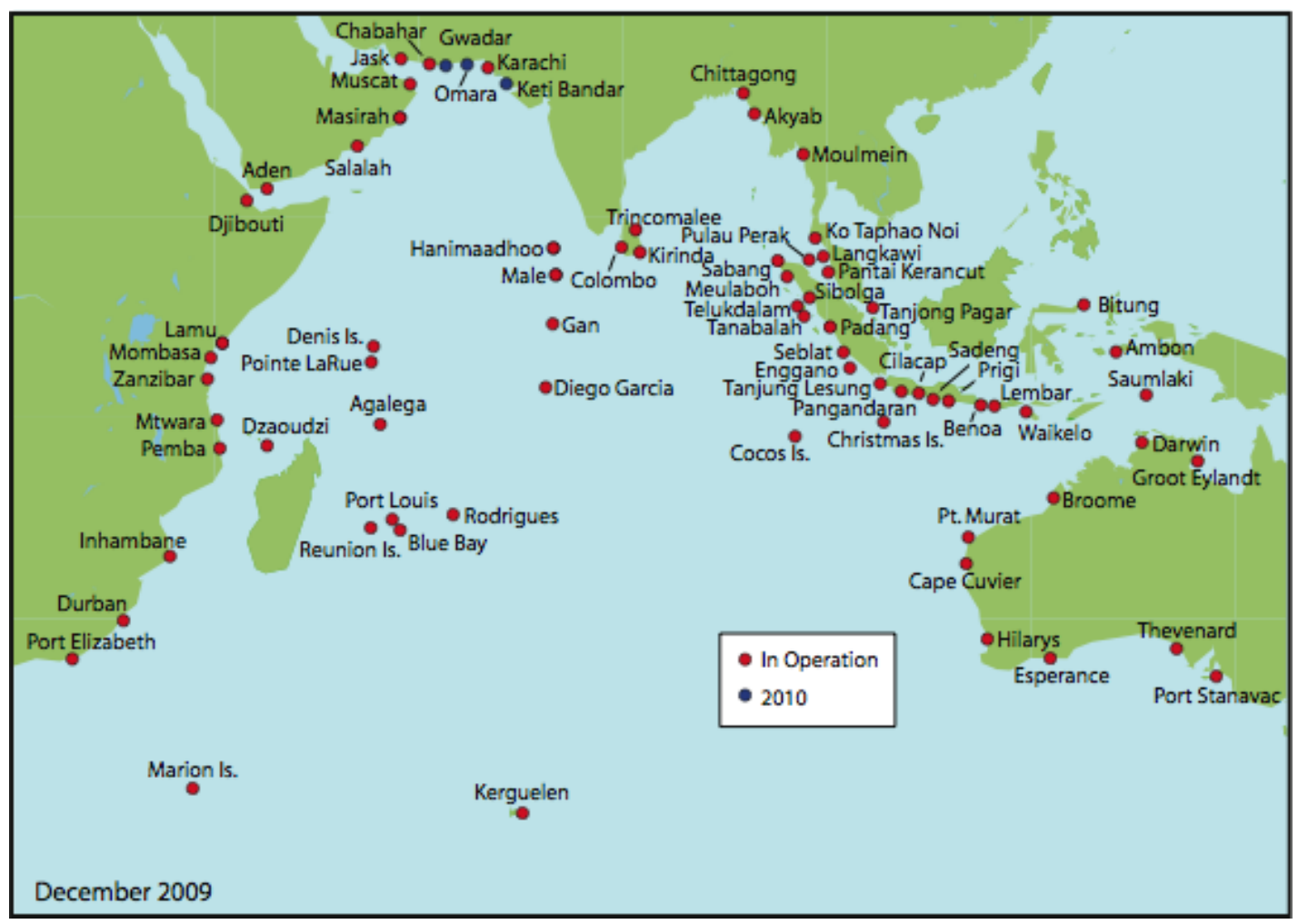

Figure 2. Sea level network of the Indian Ocean Tsunami Warning System (IOTWS)

To better assess the ongoing status of GLOSS realtime stations, a centralized network reporting system has been implemented. The IOC and the Flanders Marine Institute (VLIZ, Belgium) have developed a web-based global sea level station monitoring service for viewing sea level data received in real time from different network operators through a number of different communications channels (Fig. 3).

The particular aims of this service are to provide information about the operational status of global and regional networks of real-time sea level stations, and to provide a display service for quick inspection of the raw data stream from individual stations. The service provides a global station monitoring service for real-time sea level measuring stations in the GCN, and the networks under the regional tsunami warning systems in the Indian Ocean, North Eastern Atlantic \& Mediterranean, Pacific and the Caribbean. The number of stations being tracked by the webservice has grown from about 25 stations at the end of 2007 to presently nearly 335 stations. The tracking tool is particularly useful for quickly identifying malfunctioning stations, which should improve the overall data return of the GCN. More information about the sea level station monitoring service is available at $\mathrm{http}: / / \mathrm{www}$. ioc-sealevelmonitoring.org.
Tide gauges have been used to monitor the stability of satellite altimeter sea surface height observations. These methods were first proposed based on the GEOSAT (GEOdetic SATellite) data and were fully developed and proven during the TOPEX/Poseidon mission. See [3] for a description of the modern formalism. In recent years the methods have been generalized and applied to all present altimeter missions, and the drift estimation calculations have become quasi-operational. At present it is possible to detect globally uniform drift in the altimetric time series at the order of a few tenths of a millimeter per year.

The accuracy and versatility of the satellite drift estimation depends primarily on having the greatest possible global coverage of tide gauges that span the altimetric time period and report on a reasonably near to real-time basis, and on having independent estimates of vertical land motion at the tide gauges. The first requirement controls random errors, while the land motion estimates control possible bias errors. The GLOSS near real-time and fast delivery stations (Fig. 1) are the majority of the tide gauge stations used in the drift estimation network. At present, however, land motion errors dominate the drift estimation error budget, and these errors in turn 
dominate the error budget for estimates for global mean sea level change from satellite altimetry. The solution to this problem is to obtain, generally from continuous GPS observations, independent estimates of land motion at as many of the GLOSS stations as possible.

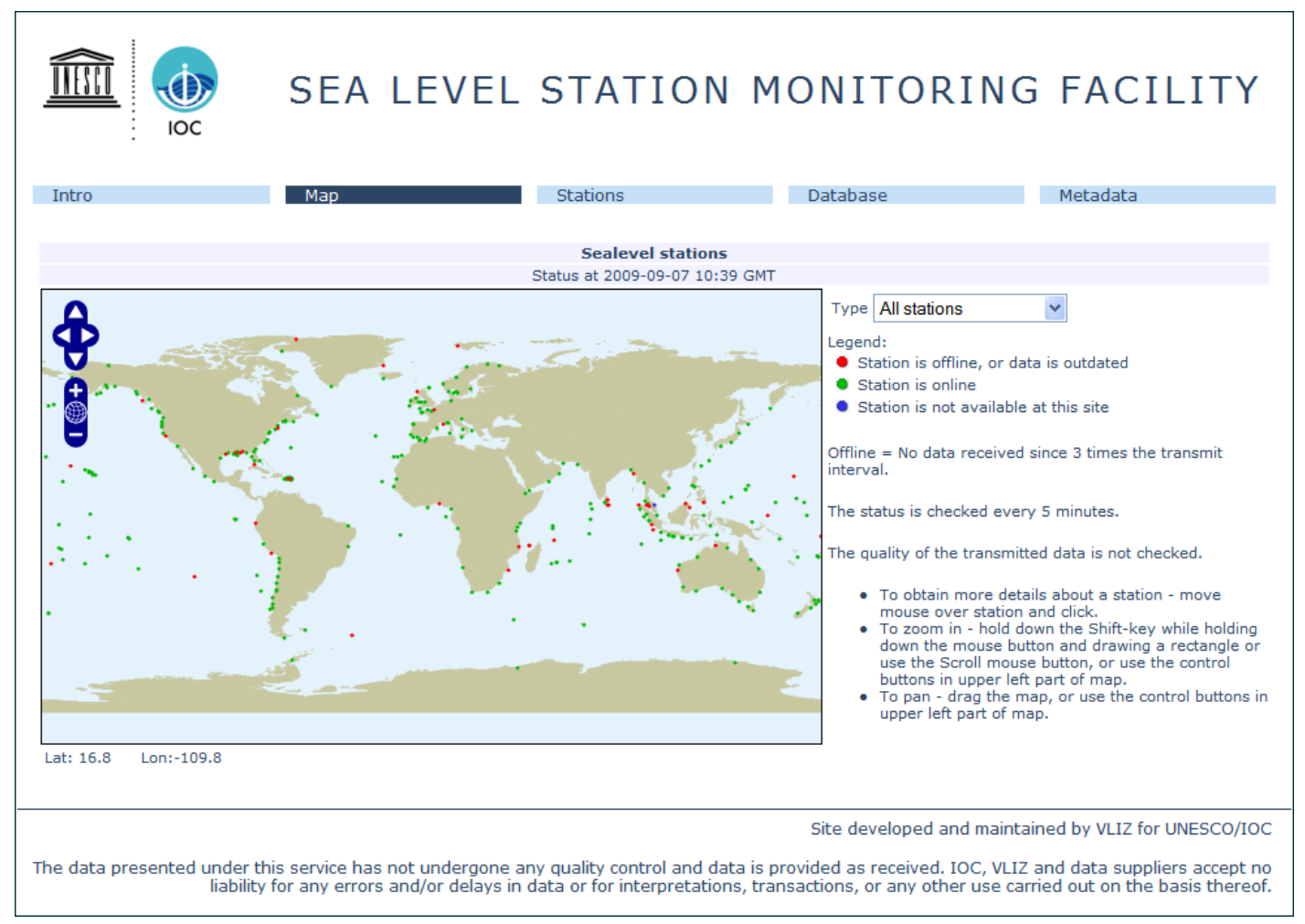

Figure 3. Web-site of the IOC Sea Level Monitoring Facility (http://www.ioc-sealevelmonitoring.org).

The number of GPS receivers at or close to tide gauges has increased remarkably to now more than 300 stations worldwide [9]. More than 100 stations now provide data to TIGA on a regular basis. The discrepancy between the available and participating stations is primarily due to the missing co-location information, or leveling between the GPS sites and tide gauge benchmarks. Other reasons are the unavailability of either GPS or tide gauge data at international data centers or the smaller distance criteria between the GPS and tide gauge site applied by TIGA.

Since its start the GLOSS program has contained a strong Training, Education and Mutual Assistance (TEMA) component. As the GLOSS program is primarily driven by global research needs, many training and implementation assistance interventions have had an overall focus on closing the gaps of observation and reporting in the GCN through (i) training (i.e. best practices (hands on training) with respect to operation of tide gauge, precise leveling to geodetic benchmarks, analysis of data, development of products); and (ii) tide gauge implementation assistance (provision of tide gauge and geodetic hardware and installation assistance).
Some of these activities have included:

(i) organization of training courses for gauge operators and specialists in sea level observation, tide gauge operation, tidal prediction, data analysis and quality control, and of specialists to make maximum local use of the gauge data; and data analysis (more than 20 courses have been convened with more than 300 trainees)

(ii) provision of a range of manuals and training materials on the hardware and data analysis freely available on the web (see http://www.gloss-sealevel.org/training/)

(iii) organization of technical expert visits concerning site selection for stations and national network developments;

(iv) provision of tide gauge equipment and spare parts;

(v) financial support for attendance at relevant international workshops, training courses, fellowship visits etc. 


\section{THE FUTURE OF GLOSS}

The GLOSS program will continue to evolve to meet the needs of the scientific research community and explore linkages to operational oceanography. Scientific oversight for the program is provided by the GLOSS Group of Experts, which meets biannually to assess network status, data acquisition and processing requirements, new observing technologies, and ties with other research programs. Following the 2006 Workshop on Understanding Sea Level Rise and Variability organized by the WCRP at UNESCO, GLOSS will work closely with the WCRP to ensure that latest sea level monitoring and research findings are transmitted to the community on a regular basis.

The GCN remains a main focus of the GLOSS program. Stations at roughly $1000 \mathrm{~km}$ intervals along the continental margins and at all the major island groups provide sufficient global coverage for a range of oceanographic applications. The GCN has never been $100 \%$ operational; even with recent advances only $75 \%$ of GCN stations report data regularly to the GLOSS Data Centers. An updated GLOSS Implementation Plan is in preparation that will set specific strategies for completing and maintaining the GCN. This will involve a reevaluation of the entire network, with the replacement of stations that are inherently difficult to maintain and the incorporation of new, proven stations. The reconfiguration of the GCN will be undertaken with careful consideration of the scientific requirements for the global sea level network.

Real-time data communication options are increasing and becoming more economical. The benefits of converting all GCN stations to real-time or near realtime reporting capability include improved data return as station problems are identified and addressed in a timely fashion, the ability to assimilate tide gauge data into operational models for storm surge and coastal inundation, and the support of tsunami warning and hazard monitoring. The majority of GCN stations now report in near-real time and in the future we expect nearly all stations to transfer data in this mode.

Sensors for estimating ground motion at tide gauges (continuous GPS, absolute gravity measurements [6], DORIS) are also becoming more economical and practical to install and maintain. In addition, spacebased geodetic techniques provide a means to assess ground motion on a regional scale and to extrapolate relative sea level trends from tide gauges to adjacent coastlines [1]. Estimates of absolute heights and vertical land motion trends at TGBMs should be available for all tide gauge stations in the GCN wherever possible. The subset of stations that are a high priority for climate research (GCOS) should all include in situ ground motion monitoring.

GLOSS is primarily concerned with tide gauge data for scientific research; however, GLOSS has always interacted with operational centers and programs, and at the Group of Experts 2007 meeting GLOSS committed to increased support for the tsunami warning community. The capacity for GLOSS commitment in these operational pursuits is a point of discussion. On a strategic level it is envisioned that broadening the user base for individual stations will increase national awareness to maintain the station to proper standards. In the immediate future, GLOSS will help to define standards for tsunami warning monitoring and will provide recommendations for optimal network configurations, coordinating closely with the IOC and its regional coordination groups. GLOSS will seek to maximize the mutual benefit between sea level monitoring and real-time tsunami warning by developing best practice recommendations and station designs that serve both purposes. It is expected that GLOSS will play a larger role in gathering and serving high frequency datasets $(\sim 1$ minute sample period) that are used for tsunami model validation and testing, and tsunami research.

From the start GLOSS has been concerned with a subset of the global tide gauge network that would serve as a backbone of distributed stations. As database capabilities increase and data communication becomes more automated, there is a growing sense that GLOSS should serve as the central data assembly and archiving center for all high quality tide gauge datasets that are freely available, similar to the role that PSMSL plays for monthly-averaged time series. One possible scenario is to position the Sea Level Monitoring Facility at VLIZ as the gateway for all high frequency datasets available over the GTS and Internet transfer sites, from which point data would flow to the existing GLOSS centers.

An ongoing challenge for GLOSS is station sustainability. It is common for a short-term aid program or tsunami initiative to lead to a welcome expansion of the GCN. This was demonstrated in the Indian Ocean following the 2004 tsunami, and also around the African continent through the efforts of the ODINAFRICA project. Few of these programs; however, have a long-term operation and maintenance strategy or capability. It is hard to attract aid funds simply to maintain existing infrastructure. Although water level sensors and data acquisition equipment are available now from private vendors, the operation of the station as a whole requires an attention to detail, particularly in 
maintaining datum control, which is hard to sustain unless regular and routine maintenance is available by a dedicated staff of technicians. For small countries, it is financially impractical and time inefficient to maintain a staff to look after in some cases only one or two national tide gauge stations. Moreover, centralized groups like the UHSLC will find it more and more difficult to service a global network if travel costs continue to rise.

The most feasible solution lies in improved regional collaboration and coordination targeted at operations. The notion of regional sub-networks has long been promoted by GLOSS, but there are few working models. Resources required to run regional initiatives are not minor, and they need a long time horizon to develop. We recommend that GLOSS should continue to provide international coordination in the form of Group of Experts meetings, sea level implementation team meetings and workshops, a real-time data facility, the intergovernmental umbrella, and the data management and communication infrastructure. A regional approach would be most effective through a shared technical resource, whereby trained technicians would provide ongoing support for a manageable set of stations (visits every 1-2 years) within each region. This would include servicing tsunami warning as well as sea level components of the network, although ideally a given station would serve both whenever possible. How such a technical infrastructure might be organized and sustained, and how to fund this service are challenges that GLOSS needs to address.

Finally, GLOSS has a proven track record of supporting and complementing satellite altimetry by providing fast delivery data (ALT) that are used to monitor the stability of the satellite measurements, by continuing the long-term records (LTT) that provide the context for altimetric estimates of low frequency sea level change, and by providing coverage across key choke points (OC) where the small spatial scales of the circulation fields limit the utility of the satellite observations. The combination of the in situ GLOSS program and the various satellite altimetry missions is arguably a model for other observing systems, present and future.

\section{REFERENCES}

1. Brooks, B.A., Merrifield, M., Foster, J., Werner, C. L., Gomez, F., Bevis, M. \& Gill, S. (2007). Space geodetic determination of spatial variability in relative sea level change, Los Angeles basin, Geophys. Res. Lett. 34, L01611, doi:10.1029/2006GL028171.
2. Merrifield, M.A., Merrifield, S.T. \& Mitchum, G.T. (2009). An anomalous recent acceleration of global sea level rise, J. Climate, 22, doi:10.1175/2009JCLI2985.1.

3. Mitchum, G.T. (2000). An improved calibration of satellite altimetric heights using tide gauge sea levels with adjustment for land motion. Mar. Geodesy 23, doi:10.1080/01490410050128591.

4. Mitchum, G. T., Nerem, R. S., Merrifield, M. A. and Gehrels, W. R. (2010) Modern Sea-Level-Change Estimates, in Understanding Sea-Level Rise and Variability (eds J. A. Church, P. L. Woodworth, T. Aarup and W. S. Wilson), Wiley-Blackwell, Oxford, UK. doi:10.1002/9781444323276.ch5.

5. Schöne, T., Schön, N. \& Thaller, D. (2009). IGS Tide Gauge Benchmark Monitoring Pilot Project (TIGA): Scientific benefits. J. Geod. 83, 249-261.

6. Williams, S.D.P., Baker, T.F. \& Jeffries, G. (2001). Absolute gravity measurements at UK tide gauges. Geophys. Res. Lett. 28 (12), 2317-2320.

7. Woodworth, P.L., Le Provost, C., Rickards, L.J., Mitchum, G.T. \& Merrifield, M. (2002). A review of sea-level research from tide gauges during the World Ocean Circulation Experiment. Oceanography and Marine Biology: An Annual Review, 40, 1-35.

8. Woodworth, P. \& Player, R. (2003). The Permanent Service for Mean Sea Level: An update to the $21^{\text {st }}$ century. J. Coastal Res. 19(2), 287-285.

9. Wöppelmann G., Aarup, T. \& Schöne, T. (2007). An inventory of collocated and nearly-collocated CGPS stations at tide gauges. Progress report (as of July 25,2007 ) on the survey carried out under the GLOSS program of IOC/UNESCO, available at: http://www.sonel.org/-Documentation-.html.

10. Wöppelmann, G., Letetrel, C., Santamaria, A., Bouin, M.-N. , Collilieux, X., Altamimi, Z., Williams, S. D. P. \& Martin Miguez, B. (2009). Rates of sealevel change over the past century in a geocentric reference frame. Geophys. Res. Lett. 36, L12607, doi:10.1029/2009GL038720. 